\title{
A vulnerabilidade externa em tempos de instabilidade: avaliando a liquidez e a solvência da economia brasileira entre 2007 e 2013.
}

\author{
Daniela Magalhães Prates* \\ André Moreira Cunha**
}

Resumo: O presente artigo tem por objetivo analisar a evolução recente das contas externas brasileiras, tendo em vista o quadro de instabilidade que marca a economia internacional desde meados de 2007. Dá-se ênfase para a avaliação de indicadores de liquidez e solvência externa, com a utilização de medidas mais amplas do que as usualmente adotadas na literatura.

Palavras-chave: vulnerabilidade externa, liquidez, solvência, economia brasileira.

Classificação JEL: F2; F3.

\footnotetext{
* Professora Associada do Instituto de Economia da UNICAMP e Pesquisadora do CNPq.

E-maill: daniprates@eco.unicamp.br

** Professor Associado do Departamento de Economia e Relações Internacionais da UFRGS e Pesquisador do CNPq

E-mail: amcunha@hotmail.com
} 


\section{Introdução}

O presente artigo tem por objetivo analisar a evolução recente das contas externas brasileiras, tendo em vista o quadro de instabilidade que marca a economia internacional desde meados de 2007. Busca-se contribuir para a discussão recente sobre a vulnerabilidade externa, por meio do cálculo de indicadores mais amplos do que os usualmente empregados na literatura (BIS, 2013; BCB, 2013; Morgan Stanley, 2013; FED, 2014). Evidências da deterioração da situação das contas externas brasileiras nos últimos anos (retratadas pelo resultado do balanço de pagamentos) são, principalmente, a trajetória ascendente do déficit em transações correntes (DTC) desde 2009, e o primeiro déficit do balanço de pagamentos desde 2000, no ano de 2013 (BCB, 2014).

O tema aqui enfatizado é de extrema relevância diante do início, em janeiro de 2014, do chamado tapering - termo utilizado para designar a desmontagem gradual da política de afrouxamento quantitativo (em inglês, quantitative easing - QE) do banco central estadunidense (Federal Reserve Fed). Ademais, o Brasil foi incluído, ao lado da Turquia, África do Sul, Índia, Indonésia, no grupo dos "cinco frágeis", que seriam os mais vulneráveis à progressiva normalização das condições monetárias nos Estados Unidos devido aos elevados déficits em transações correntes, altas taxas de inflação e/ou desaceleração do crescimento (Morgan Stanley, 2013; FED, 2014).

Nossos principais resultados podem ser assim resumidos: na comparação com a situação vigente antes da crise financeira global de 2008, o Brasil é hoje menos vulnerável do ponto de vista da liquidez externa; em contrapartida, a condição de solvência externa piorou. Após breve contextualização do ambiente externo (seção 2), a seção 3 descreve a metodologia de cálculo e apresenta os indicadores de vulnerabilidade externa. Seguem as considerações finais.

\section{A Evolução Recente da Economia Mundial}

Ao longo do ano de 2013, com projeções no início de 2014, a economia mundial tem sido marcada pelo ajuste da política monetária dos Estados Unidos. Embora tenha começado, como esperado, num ritmo mensal bem suave-de US\$ 10 bilhões (redução da compra de ativos de US $\$ 85$ bilhões para US $\$ 75$ bilhões), que será mantido em fevereiro - o tapering, ao lado divulgação de indicadores desfavoráveis sobre o desempenho da economia chinesa, desencadeou uma nova fase de turbulência nos mercados cambiais e acionários de algumas economias emergentes na última semana de janeiro. Além da Argentina, em crise cambial aberta, também foram especialmente atingidos Turquia, África do Sul, Índia, Indonésia e Brasil, grupo que passou a ser denominado de "os cinco frágeis" (fragile five) (Morgan Stanley, 2013), dados seus elevados déficits em transações correntes, altas taxas de inflação e desaceleração do crescimento. A resposta dos 
governos desses países aos ataques especulativos contras suas moedas e ativos financeiros no final de janeiro foi o aperto na política monetária, que contribuiu para acalmar os ânimos dos investidores internacionais. Vale mencionar que, dos "cinco frágeis", somente no Brasil tinha iniciado uma nova fase de alta da meta da taxa de juros básica em 2013.

De acordo com os cenários básicos para 2014 tanto do Fundo Monetário Internacional - FMI (IMF, 2014) como do Banco Mundial (World Bank, 2014), esses ânimos devem se manter contidos ao longo do ano. Esses cenários preveem um impacto suave do "tapering" sobre os fluxos privados de capitais para os países emergentes e em desenvolvimento em 2014. Na estimativa do Banco Mundial, esses fluxos devem recuar de 4,6\% do PIB em 2013 para 4,2\% do PIB em 2014, patamar ainda elevado em termos históricos. Esses cenários também projetam uma aceleração do crescimento da economia mundial de 3\% em 2013 para 3,7\% em 2014. A hipótese subjacente é que a trajetória de recuperação nas economias avançadas em curso desde meados de 2013 ganhará impulso adicional no corrente ano, resultando numa taxa de expansão 0,9 p.p superior à registrada em 2013 (1,3\% para 2,2\%). No caso dos países emergentes e em desenvolvimento, a aceleração será mais modesta, de somente 0,5 p.p (4,8\% para 5,3\% para o World Bank e 4,7\% para 5,1\% para o FMI).

Assim, nesses cenários, se, por um lado, o "tapering" afetará negativamente, embora de forma suave, as economias emergentes pelo canal das "finanças internacionais", por outro lado, a aceleração do crescimento das economias avançadas as beneficiará pelo canal da "demanda externa". Ou seja, as importações dessas economias, que iniciaram uma trajetória de recuperação em 2013, devem acelerar em 2014. Segundo o FMI, seu ritmo de expansão deve atingir $3,4 \%, 2$ pontos percentuais (p.p) acima da estimativa para 2013. Já o volume total do comércio internacional (avançadas e emergentes) deve avançar cerca de 4,5\%. Esse efeito positivo, contudo, se concentrará nos países exportadores de bens manufaturados. O valor unitário exportado desses bens deve crescer 1,6\% em 2014, após dois anos consecutivos de queda (1,2\% em 2012 e 1,4\% em 2013), segundo o Banco Mundial.

Já nas economias emergentes produtoras de commodities, o aumento das quantidades exportadas será atenuado ou anulado pela queda dos preços desses bens, de acordo com as projeções (nesse quesito, bastante díspares) das duas instituições multilaterais: para o FMI, a deflação dos preços das commodities não-energéticas será de 6,1\% em 2014 (frente a 1,5\% em 2013) e para o Banco Mundial de 2,6\% (contra 7,2\% em 2013). Uma das hipóteses subjacentes é a mudança na composição do crescimento da China, menos intensiva em investimento (e, assim, em importações de produtos básicos).

O efeito líquido desses canais (finanças internacionais, demanda externa e preços das commodities) sobre cada país emergente dependerá de vários fatores, dentre os quais, a situação das contas externas (resultado em conta corrente, composição da pauta de comércio exterior e dos fluxos de capitais), o tamanho e composição do passivo externo líquido (PEL), o grau de abertura financeira e de liquidez dos mercados cambiais e acionários, a participação dos investidores 
estrangeiros nos mercados financeiros domésticos e grau de endividamento em moeda estrangeira.

\section{A Evolução da Vulnerabilidade Externa da Economia Brasileira, 2007-2013}

Para contribuir com o debate sobre os impactos da instabilidade da economia global sobre o desempenho do setor externo do Brasil, a presente seção apresenta um conjunto de indicadores de vulnerabilidade externa, que acreditamos ser mais abrangente que o utilizado nas análises recentes sobre o tema (BIS, 2013; BCB, 2013; Morgan Stanley, 2013; FED, 2014). Estas têm priorizado indicadores relacionados à dívida externa - que é comparada às reservas ou ao PIB (para mensurar, respectivamente, a liquidez e a solvência externas) -, os quais, na perspectiva aqui adotada, fornecem uma visão incompleta da vulnerabilidade externa da economia brasileira. Isso porque, a dívida externa de curto prazo é atualmente uma fração muito pequena do passivo externo de curto prazo (PECP) e a dívida externa líquida é negativa desde 2007 (devido à redução da dívida externa pública e ao acúmulo de reservas internacionais).

Um indicador sintético de liquidez externa (ou da vulnerabilidade externa no curto prazo) é a razão entre o PECP e as reservas internacionais do país (ou seja, os recursos em divisas que podem ser mobilizados no curto prazo frente a uma saída súbita de capitais externos). Além deste indicador, também foram calculados três indicadores, cuja característica comum é a utilização das reservas internacionais no denominador, se diferenciando somente na composição do numerador ${ }^{1}$, quais sejam:

- Dívida externa de curto prazo/reservas: visa avaliar se há ou não possibilidade de crise de liquidez externa por falta de moeda estrangeira para honrar a dívida externa a vencer num prazo inferior a 360 dias;

- Indicador utilizado pela agência de classificação de risco de crédito Standard \& Poors: considera no numerador as necessidades brutas de financiamento externo (NBFE), que equivalem à soma do saldo em transações correntes, com o principal vencível da dívida externa de médio e longo prazo nos próximos 12 meses e o estoque da dívida de curto prazo;

- Indicador amplo de liquidez externa: consiste na soma das NBFE com o estoque de IPE; este indicador mede a pressão potencial sobre as reservas internacionais do País no curto prazo.

1 Detalhes metodológicos sobre os indicadores, ver em: Prates, Cunha e Ferreira (2011). 
O significado de todos indicadores de liquidez que utilizam as reservas no denominador é semelhante: se o valor da razão for igual a 1, as reservas são suficientes para cobrir o estoque em questão (PECP ou dívida externa de curto prazo) e/ou as NBFE; se for inferior a 1, as reservas são mais que suficientes para cobrí-los (por exemplo, um indicador igual a 0,20 significa que somente $20 \%$ das reservas serão utilizadas); se for superior a 1, as reservas são insuficientes (por exemplo, um indicador igual a 1,20 significa que as reservas precisariam ser $20 \%$ maiores para fazer frente à pressão cambial).

$\mathrm{Na}$ comparação de 2007 com 2013, os quatro indicadores mostram uma melhora da situação de liquidez externa da economia brasileira, mas há, claramente, dois grupos com patamares bastante distintos (gráfico 1).

O primeiro grupo, que inclui os indicadores 1 e 2 , sugere uma situação favorável de liquidez externa em dezembro de 2013 (indicadores inferiores a 1), melhor até do que a registrada no limiar da crise financeira global (dezembro de 2007). Enquanto em 2007, a dívida externa de curto prazo absorvia $22 \%$ das reservas e as NBFE 24\%, em 2013 esses percentuais eram de, respectivamente, 9\% e 13\%. Em comparação ao indicador 1 (o mais utilizado nas análises recentes), o indicador 2 (Standard \& Poors) é mais abrangente pois considera no numerador, além dessa dívida, o resultado das transações correntes (que, se negativo, como no caso do Brasil, aumenta as NBFE) e o principal vencível das dívidas de médio e longo prazo no ano. Contudo, a pressão sobre as reservas exercida por esses dois últimos fatores em 2013 era bem pequena, de apenas 4\%.

\section{Gráfico 1 - Indicadores de Liquidez Externa, 2007-2013}

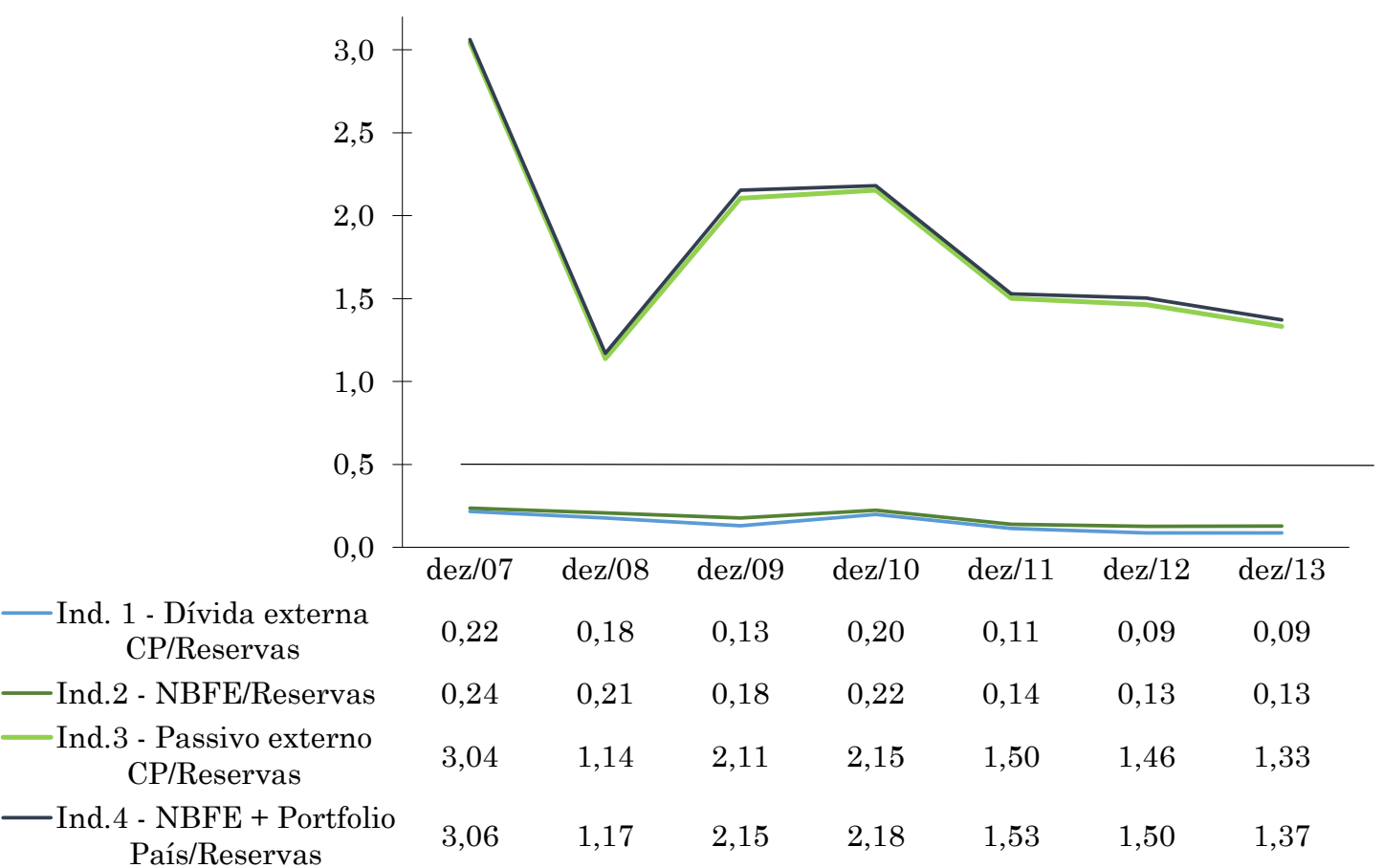

Fonte: Elaboração própria com base nos dados do Banco Central do Brasil. Nota: NBFE = Saldo em conta corrente + Dívida de curto prazo + principal vencível da dívida de médio e longo prazo. 
O segundo grupo engloba os indicadores 3 e 4, cujo denominador comum é a inclusão, no numerador, do estoque de IPE no país. Ambos indicam uma situação desfavorável de liquidez externa, pois superam 1, ou seja, as reservas são insuficientes para fazer frente seja ao PECP, seja à soma "NBFE + estoque de IPE no país". Contudo, nos dois casos, o grau de cobertura cambial era muito maior em 2013 do que em 2007: neste mês, o PECP superava em 204\% o estoque de reservas, percentual que recuou para $33 \%$ em 2013; no caso da soma "NBFE+portfólio no país" os percentuais eram de 206\% e 37\%. Esses resultados decorreram tanto do aumento do denominador (alta de 108\% das reservas), como da redução dos numeradores (o PECP diminuiu 8,7\% e aquela soma 6,6\%).

Assim, o indicador mais a mplo (indicador 4) revela que, embora a situação de liquidez externa da economia brasileira seja melhor do que a vigente antes da crise financeira global, nosso "colchão de segurança" ainda é 37\% insuficiente para cobrir a demanda potencial de divisas (medida pela soma "NBFE+portfólio no país", ou seja, o numerador do indicador 4). Contudo, também é preciso levar em consideração a composição do PECP, que é atualmente mais favorável por dois motivos. Por um lado, a participação da dívida de curto prazo no total - que gera compromissos em divisas (juros e amortizações) e envolve descasamento de moedas - recuou ainda mais no período analisado $(7,1 \%$ em dez/2007 para $6,6 \%$ em dez/2013) como reflexo do alongamento do prazo da dívida externa em resposta aos controles de capitais vigentes em 2011 e 2012. Por outro lado, como destaca Biancareli (2012), no caso dos investimentos de portfólio no país (que respondiam por mais de 90\% do PECP nos dois momentos), quando há liquidação de posições dos investidores estrangeiros em moeda doméstica num regime de câmbio flutuante, o valor em moeda estrangeira dessa modalidade de passivo externo diminui em função tanto da queda dos preços dos ativos em moeda doméstica como da depreciação cambial provocada pela saída de capitais. É exatamente essa desvalorização do estoque de ativos financeiros de não residentes no país, medida em US\$, que explica a queda dos indicadores de liquidez em 2008.

Todavia, a composição atual do PECP - predominância de IPE no país, viabilizada pelo aprofundamento da abertura financeira após o ano de 2000 também tem uma implicação negativa: ela reforça as correias de transmissão da instabilidade gerada nos mercados financeiros internacionais (que condicionam as decisões de alocação de portfólio dos investidores não residentes) para o mercado financeiro doméstico.

Já para avaliar a situação de solvência externa de um país (Prates, Cunha e Ferreira, 2011), um indicador fundamental é a razão entre o passivo externo líquido (PEL) e as exportações. Isto porque, no caso dos países em desenvolvimento, como o Brasil, as exportações são a fonte de geração autônoma de divisas, necessárias para pagar a taxa de remuneração do PEL. Como destacam Medeiros e Serrano (2001), para que essa razão não tenha uma trajetória explosiva, o ritmo de expansão das exportações precisa ser superior a essa taxa. $\mathrm{O}$ valor da razão indica o número de anos, dado um determinado fluxo de exportação (acumulado em 12 meses), necessário para o pagamento do PEL. 
Vale mencionar que várias analises utilizam o PIB ao invés das exportações no denominador dos indicadores de solvência externa, o que carece de sentido, pois o PIB não equivale à capacidade de geração de moeda estrangeira de um país.

No caso do Brasil, cujo desempenho exportador na última década ancorouse nas vendas externas de commodities, também é importante incluir na análise a capacidade de geração de divisas pela indústria de transformação (IT). Diante do esgotamento da trajetória de alta dos preços desses bens e das mudanças em curso na China - desaceleração e mudança no padrão de crescimento, que resultarão em menor demanda por produtos agrícolas e minerais -, a trajetória futura das exportações brasileiras (e nossa capacidade de geração de divisas) será mais dependente do desempenho das vendas externas da IT. Assim, além do indicador tradicional PEL/exportações, três indicadores adicionais de solvência externa foram calculados: (i) Serviço do PEL/exportações - este é um indicador alternativo ao PEL/exportações para avaliar a sustentabilidade ou não de uma trajetória de acúmulo de passivos externos, que depende exatamente da relação entre as exportações e o serviço do PEL; (ii) PEL/exportações da IT - Serviço do PEL/exportações da IT.

Assim como no caso da situação de liquidez externa, a análise privilegiará a comparação da situação de solvência externa em dezembro de 2013 e no contexto pré-crise financeira global (dezembro de 2007). Vale lembrar que no caso dos indicadores de solvência, a queda em 2008 dos indicadores que têm o PEL no numerador também decorreu dos efeitos da variação na taxa de câmbio e nos preços dos ativos domésticos.

A evolução dos indicadores mostra que, ao contrário da situação de liquidez externa, a de solvência sofreu deterioração na comparação entre 2007 e 2013. Embora o indicador 1 (PEL/exportações totais) tenha permanecido praticamente no mesmo patamar (2,98 e 2,7, respectivamente), o indicador 2 (PEL/exportações da IT) avançou de 4,63 para 5,19 no mesmo período. Isso quer dizer que, enquanto seriam necessários 2,7 anos para pagar o PEL com o fluxo anual de exportações de bens e serviços de 2013, considerando somente as exportações da indústria de transformação, seriam necessários mais de 5 anos. Os indicadores 3 e 4, que consideram o serviço do PEL no numerador, também indicam piora nessa situação, com destaque para o indicador 4 , que aumentou de 0,37 para 0,58; ou seja, em 2013, o serviço do PEL "consumia" 58\% das exportações da indústria de transformação (ver gráfico 2). 
Gráfico 2 - Indicadores de solvência externa, 2007-2013

*Ind.1=PEL/exp.totais

$\rightarrow$ Ind.2=PEL/exp.IT

$\rightarrow$ Ind.3=Serviço PEL/exp.totais

—-Ind.4 =Serviço PEL/exp.IT

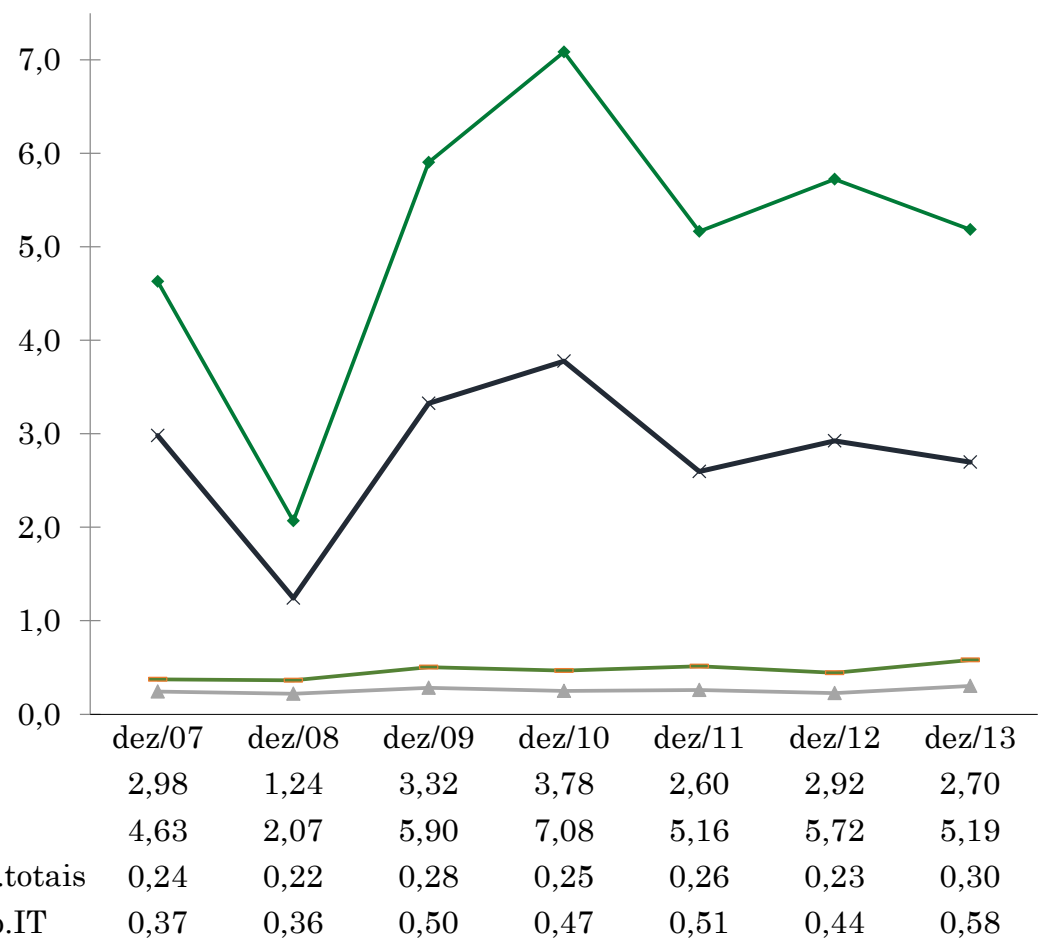

Fonte: Elaboração própria com base nos dados do Banco Central do Brasil. Nota: IT = Indústria de Transformação.

Ao se analisar as variações anuais de tais indicadores, é possível constatar que após o desempenho favorável em 2010 e 2011, beneficiado pela recuperação da economia mundial sob a liderança das economias emergentes (sobretudo, China) e pelo novo boom de preços das commodities, as exportações totais de bens e serviços recuaram em 2012 e 2013, num contexto de reversão desse boom e de desaceleração da economia chinesa (e do seu apetite por commodities). Em termos acumulados (variação entre 2007 e 2013) o pior desempenho dos indicadores que consideram as exportações da indústria de transformação no denominador é explicado pela sua menor taxa de crescimento (23\%) em relação às exportações totais $(52,4 \%)$, ao PEL $(37,8 \%)$ e ao serviço do PEL (90,7\%). Esse aumento expressivo $(90,7 \%)$ da taxa de remuneração do PEL - que é motivo de preocupação, assim como o baixo dinamismo das vendas externas da IT - está associado, entre outros fatores, ao aumento das remessas de lucros e dividendos pelas filiais da ETs, pressionadas pela redução da rentabilidade nos países de origem no contexto da grande recessão.

\section{Considerações Finais}

O desempenho recente das economias mundial e brasileira segue condicionado pelos desdobramentos da crise financeira de 2007/2008, cujo ponto culminante foi a falência banco de investimento Lehman Brothers Holdings 
Inc. Aquilo que parecia ser um problema localizado no mercado hipotecário dos Estados Unidos, converteu-se na mais grave crise financeira dos últimos 80 anos. Para se colocar em perspectiva, em 2009 o produto interno bruto (PIB) mundial experimentou sua primeira contração desde a Segunda Grande Guerra (Unctad, 2013; IMF, 2014; World Bank, 2014). No último trimestre de 2008 e ao longo de 2009, as principais economias maduras e emergentes lançaram mão de um amplo leque de medidas monetárias, creditícias e fiscais que evitaram uma retração ainda mais intensa. Ao invés de uma nova grande depressão, passouse a conviver com um ambiente de baixo crescimento, elevado desemprego e volatilidade exacerbada nos mercados financeiros.

O Brasil não foi uma exceção. Após a crise, o governo central seguiu a tendência internacional de adoção de estímulos monetários, creditícios e fiscais contundentes, de modo a reverter a tendência depressiva. Retrospectivamente, pode-se afirmar que tais iniciativas garantiram o amortecimento dos impactos da crise em 2009, quando o PIB experimentou contração de 0,3\%. Porém, já em 2010 a expansão veio vigorosa e o crescimento foi de 7,5\%. Em 2011, o governo central conduziu um aperto fiscal, que veio se somar à retomada da política monetária restritiva. Isto porque, havia sinais de que a aceleração do crescimento vinha acompanhada de pressões inflacionárias significativas.

O ambiente internacional foi-se tornando cada vez menos favorável a partir de 2011, diante: (i) da crescente instabilidade nos mercados financeiros frente aos problemas de endividamento das economias europeias; (ii) do baixo crescimento do conjunto das economias maduras, particularmente os Estados Unidos, agravada pelos efeitos da crescente tensão política do congresso estadunidense sobre a situação fiscal do país; e (iii) da desaceleração no crescimento das principais economias emergentes, particularmente a China, o que comprometeu o bom desempenho do comércio mundial de commodities minerais, energéticas e alimentos.

A aposta redobrada nos estímulos fiscais, por meio, principalmente, de desonerações tributárias diversas, e na atuação dos bancos públicos, como fontes estratégicas para a sustentação do crédito para investimentos de longo prazo, não têm garantido a manutenção de taxas robustas de crescimento. Assim, o quadro econômico brasileiro ao término de 2013 não era animador, caracterizando-se pelo baixo crescimento com perda de vitalidade nos fundamentos fiscais e externos.

É neste contexto que o presente trabalho procurou analisar o desempenho recente da vulnerabilidade externa da economia brasileira, tendo em vista o quadro de instabilidade internacional vigente desde meados de 2007. Constatouse a deterioração da solvência externa, ainda que a economia brasileira não pareça ter problemas graves de liquidez.

Ademais, mesmo que a situação de liquidez seja relativamente confortável não se pode descartar que o desempenho externo do Brasil possa se deteriorar ainda mais. Nos termos das análises da Unctad (2013), FMI (IMF, 2014), Banco Mundial (World Bank, 2014), dentre outros, o ano de 2014 deverá ser marcado pela alternância de fases de turbulência e calmaria nos mercados 
financeiros internacionais, dados os riscos que ainda permeiam o desempenho da economia mundial, dentre as quais a ameaça de deflação nas economias avançadas, a incerteza quando à robustez do crescimento nos Estados Unidos e ao ritmo de desaceleração da China e a persistência dos problemas estruturais da área do Euro. Do ponto de vista da solvência externa, preocupam a excessiva dependência das exportações de commodities, cuja dinâmica recente dos preços não tem sido favorável, e a perda de dinamismo das exportações de manufaturas.

Como indicam vários estudos (IMF, 2013), é significativamente alta a correlação entre o crescimento desses preços e a atividade econômica nas economias emergentes em geral e, especialmente, na China (principal importadora mundial de produtos primários). As commodities metálicas foram as mais prejudicadas por essa desaceleração, que envolveu o setor de construção civil chinês, importante consumidor desses bens; ademais, os preços elevados dos anos precedentes estimularam o aumento da oferta. A desmontagem de posições pelos investidores financeiros nos mercados futuros de commodities no segundo e terceiro trimestres de 2013 , em resposta às incertezas quanto ao momento de início do "tapering", também contribuiu para a queda dos preços (Unctad, 2013).

O crescimento das exportações da indústria de transformação em 2013 (1,3\% contra a queda de $0,4 \%$ nas exportações totais) - beneficiado pela depreciação cambial e pela recuperação das economias avançadas - foi um dado positivo, mas insuficiente para compensar o efeito negativo da queda dos preços das commodities. Em 2014, caso essa recuperação tenha continuidade (como prevêem os cenários básicos do FMI e do Banco Mundial), essas exportações podem ganhar um impulso adicional, que, todavia, pode ser atenuado (ou até anulado) pela crise cambial na Argentina, principal destino das nossas exportações industriais.

Assim, para garantir uma trajetória sustentável de expansão das vendas externas de manufaturas - fundamental para evitar uma situação de insolvência externa -, ações de política econômica são necessárias. Além de evitar um novo movimento de apreciação da moeda doméstica, o governo deve promover uma melhor coordenação junto à iniciativa privada para estimular os investimentos e a reindustrialização do país, simultaneamente à intensificação das negociações comerciais para a (re)inserção da indústria brasileira nas cadeias globais de valor ${ }^{2}$.

\footnotetext{
2 Vale lembrar que as vantagens para o país das exportações de produtos da indústria de transformação comparativamente às commodities (inclusive industriais): geram efeitos positivos e cumulativos sobre a produtividade da indústria, são menos sujeitas às oscilações de preços nos mercados internacionais e têm maior elasticidade-renda da demanda (Unido, 2013; WTO, 2013).
} 
A Vulnerabilidade Externa em Tempos de Instabilidade: avaliando a liquidez e a solvência...

\section{Referências}

BCB (2014) Nota para imprensa setor externo, janeiro. Brasília: Banco Central do Brasil.

BCB (2013). Relatório de Inflação, dezembro. Brasília: Banco Central do Brasil.

Biancareli, A. M. (2012) Uma nova realidade do setor externo brasileiro em meio à crise internacional. Texto para Discussão n. 13, Rede Desenvolvimentista, dez.

BIS (2013). 83 ${ }^{\text {rd }}$ Annual Report. Basle, Bank for International Settlements.

FED (2014). Monetary Policy Report, February 11, 2014 - Board of Governors of the Federal Reserve System. Disponível em: http://www.federalreserve.gov/ monetarypolicy/files/20140211_mprfullreport.pdf (acesso em 18/02/2014).

IMF (2014) World Economic Outlook Updated, January 2014. . Washington D.C.: International Monetary Fund. Disponível em: http://www.imf.org.

IMF (2013) World Economic Outlook, October 2013. Washington D.C.: International Monetary Fund. Disponível em: http://www.imf.org.

Medeiros, C. A; Serrano, F. (2001). Inserção externa e desenvolvimento. Fiori, José Luis (org.) Polarização mundial e crescimento. Editora Vozes: Petrópolis.

Morgan Stanley. Global Outlook, August, 2013. Disponível em: http://www. morganstanleyfa.com/public/projectfiles/dce4d168-15f9-4245-9605-e37e2caf114c. pdf (acesso em 01/02;/2014).

Prates, D. M.; Cunha, A. M.; Ferreira, A. N. (2011). O Balanço de Pagamentos. In: Bêrni, D. A.; Lautert, V. (Org.). Mesoeconomia: lições de contabilidade social: a mensuração do esforço produtivo da sociedade. Porto Alegre: Bookman.

UNCTAD (2013). Trade and Development Report. New York: UNCTAD.

UNIDO (2013). Competitive Industrial Performance Report 2012/2013. Vienna: United Nations Industrial Development Organization.

World Bank (2014). Global Economic Prospects: coping with policy normalization in high-income countries, January, 2014. Washington D.C: World Bank. Disponível em: http:// www.worldbank.org.

World Trade Organisation (Wto, 2013). World Trade Report 2013: Factors shaping the future of world trade. Geneva: WTO. 
